that drug. The explanation which suggests itself to me, though perhaps not based on scientific reasoning, is that when once cholera is established absorption is more and more impaired, if not altogether retarded, so that the amount of opium accumulates, and that when recovery begins to take place, and the power of absorption is regained, the aggregate amount of opium acts as an overdose. Granting then the accuracy of this zone theory, the natural deduction is that treatment is of little use ; but this is not so in practice, for though indisputably no appreciable benefit follows the administration of any particular drug, nevertheless remedies are beneficial in supporting the strength, allaying the nervous fear, relieving the pain, mitigating the severity of the symptoms, and correcting the predisposing causes.

A detailed account of a treatment which must vary under different circumstances would be of little interest, but a description of the main features wili probably prove of use. At the very commencement of the disease, prior to any manifest evidence of collapse, a dose of opium in com bination with castor oil or an astringent should be given; but one and only one dose, and not under any pretext whatsoever is any more to be given until convalescence is thoroughly established. Cold but not iced water, acidulated with vinegar or dilute sulphuric acid, should be given $a d$ libitum, notwithstanding the fact that it is speedily vomited. To attempt to quench the craving for a long drink by small lumps of ice is heart-rending treatment, and merely substitutes retching for vomiting without the transient relief which follows the rejection of the fluid. The body should be enveloped in a wet sheet, or immersed in a soda bath, and the cramps relieved by constant kneading of the muscles, a process which is of greater efficacy than simple rubbing of the surface. Occasionally chloroform inhalation is imperative, but the administration should depend more on the frequency of recurrence than on the severity of the cramps. Tepid water in large quantities should be given by means of an enema, oftentimes repeated, In the early stage of the disease, and so long as the power of absorption is not quite arrested, food should be given frequently, and in very small quantities. Half a teaspoonful of equal parts of lime-water and milk-the latter is too heavy by itself-or the same quantity of chicken or beef-juice, also diluted, should be given every ten minutes during the day and night, increasing the quantity and diminishing the frequency as the patient's condition improves. Alcoholic stimulants are best avoided, though I have seen cold champagne, given a tumblerful at the time, prove grateful to the patient and apparently beneficial. The first symptom of convalescence is the presence in the bladder of a few drops of urine, which, if allowed to remain, soon become most ammoniacal. I consider this a most important guide to prognosis, for with ordinary care recovery is almost a certainty, unless, as I have already stated, large or repeated small doses of opium have previously been given. As soon, however, as the urine is detected (and I pass a catheter frequently to ascertain the progress of the case) the bladder should be repeatedly irrigated. Subsequent treatment consists of astringents and tonics. Food should still be sparingly allowed, and any restlessness controlled by small doses of henbane. The sequelæ of cholera require appropriate treatment.

I am, Sirs, yours obediently,

G. ShERMAN BIGG, F.R.C.S. Ed.,

Late Staff Surgeon, Allahabad, India.

Victoria-street, London, S.W., Sept. 1st, 1890.

"INTERNATIONAL CONSUMPTION OF MEAT." To the Editors of Thr LANCET.

SIRs,-Will you allow me to protest against the illogical reasoning of your correspondent, Mr. Yorke-Davies, in his letter anent "international meat consumption"? His attempt to attribute to the greater consumption of animal food in Australia and the United States an alleged superiority of these peoples in "go" and "energy," ignoring totally the many other more important factors which contribute towards the formation of racial characteristics, is extremely misleading. Are we then to believe that in the consumption of a larger quantity of animal albumens we hold the key to the striking difference, mental and physical, between a Chinaman who lives largely on rice and a beef-eating Australian or American? Were the ancient Romans, who conquered the known world, and the ancient Greeks, who astound us by their intellectual might, phenomenal meat consumers? I trow not, if the climatic conditions for existence were then as they exist now in Greece and Italy. Has your correspondent ever tried to eat large quantities of animal food during the sub-tropical heat of an Italian summer? Your correspondent instances the energy of a meat-eating Yorkshire labourer. How, then, does he explain the power for physical exertion in a Scotch farm labourer during harvest time, who lives almost solely on porridge? Correct dieting, as Mr. Yorke-Davies remarks, reduces obesity, but it does not follow that, because some unfortunate people possess an abnormal power of converting farinaceous food into fat, therefore a race which lives largely on such diet must become similarly afflicted, not to mention lacking in "energy" and "go." May it not be that the low rate of mortality in Queensland, which another of your correspondents, Dr. Drysdale, refers to, is due among other causes, not so mueh to the "abundant supply of digestible animal albumens" as to the fact that the food consumption is far more equally distributed amongst the population than is the case with us? Think also of the enormous differences in the conditions of life between a largely agricultural population like that of Queensland and the teeming millions of our smoke-haunted manufacturing towns.

Dartford, Aug. 30th, 1890. am, Sirs, yours faithfully,

\section{VERTICAL DISLOCATION OF THE PATELLA.} To the Editors of THE LANCET.

SIRS,-A few days after publishing my notes on a case of vertical dislocation of the patella, in THE LANCET of July 26th, my attention was called by a lay correspondent, who had read my case, to the following interesting narrative of what one would imagine was a similar case of injury ; at all events, if not a "vertical" dislocation, it was evidently an irreducible one.

The story is narrated in the Chronicle of Jocelin, during the time of Abbot Hugo, of the Monastery at Bury St. Edmunds. The Latin context will be found in the Publications of the Camden Society. The following is a translation:- "It came into Hugo's mind to go to St. Thomas's to pray, and during his journey, near Rochester, he had a sad fall, so that the patella left its proper position and became fixed to part of the knee. The doctors met together and put him to great pain in various ways, but in vain. He was carried back to us in a horse-litter (or bier), most carefully attended, as became his position. Why should I say more? His leg mortified, the pain mounted to his heart, and a tertian fever supervened, in the fourth attack of which he died. And just before he expired his servants pilfered all his goods and chattels, so that nothing was left in the Abbot's house but tripods and tables, too heavy to carry off!" I am, Sirs, yours faithfully,

Edward A. PigGoTT, L.R.C.P. \& S. Edin., \&c. Clare, Suffolk, Sept. 4th, 1890

\section{LIVERPOOL}

(FROM OUR OWN CORRESPONDENT.)

\section{Notification of Disease.}

ON the 1st inst. the Infectious Disease (Notification) Act, 1889 , came into force in this city and port, this having been resolved upon at a special meeting of the City Council held on Jan. 8th last. Circulars giving full details and forms of certificates have been sent to all medical practitioners, and others to whom the Act refers. Speaking generally, it may be said that the Act is not viewed favourably by local medical practitioners. It is felt that the duties of the latter cease when they have certified that the disease is an infectious one, and that the actual notifying of the disease to the medical officer of health should be left to the householder. But now that the Act has become law there can, of course, be no doubt that it will be loyally regarded, and it only remains to be seen what the result will be. There have been some few cases of fever in a narrow, central street, but it has shown no tendency to spread. It will be specially interesting to observe how far 